\title{
PENERAPAN PENDEKATAN SINERGIS BERBASIS KELOMPOK DALAM MENINGKATKAN HASIL BELAJAR SISWA DALAM PEMBELAJARAN MATEMATIKA
}

\author{
Sukari \\ SDN 2 Marikangen Cirebon, Indonesia \\ sukari63@gmail.com
}

\begin{abstract}
This study aims to improve mathematics learning outcomes in learning the operation of calculating mixed fractions in class IV SDN 2 marikangen, Cirebon. This type of research is a Classroom Action Research with research subjects are students in grade IV SDN 2 marikangen, Cirebon. Data on research results obtained from observations and learning outcomes tests. The data obtained were analyzed descriptively quantitative and descriptive qualitative. The results showed that the average learning outcomes using a group-based synergistic approach had increased. Thus it can be concluded that the application of the group-based synergistic approach can improve student learning outcomes in mathematics learning in Mixed Count Operational Materials in class IV SDN 2 marikangen..
\end{abstract}

Keywords: synergistic approach, group learning, learning outcomes, mathematics.

\begin{tabular}{l} 
ABSTRAK \\
\hline Penelitian ini bertujuan untuk meningkatkan hasil belajar matematika dalam pembelajaran \\
operasi hitung bilangan pecahan campuran pada siswa kelas IV SDN 2 marikangen, Cirebon. \\
Jenis penelitian ini adalah Penelitian Tindakan Kelas dengan subyek penelitian adalah siswa kelas \\
IV SDN 2 marikangen, Cirebon. Data hasil penelitian diperoleh dari observasi dan tes hasil \\
belajar. Data yang diperoleh dianalisis secara deskriptif kuantitatif dan deskriptif kualitatif. Hasil \\
penelitian menunjukkan bahwa rata-rata hasil belajar menggunakan pendekatan sinergis berbasis \\
kelompok mengalami peningkatan. Dengan demikian dapat disimpulkan bahwa Penerapan \\
Pendekatan Sinergis Berbasis Kelompok dapat meningkatkan hasil belajar siswa dalam \\
pembelajaran matematika pada Materi Operasi Hitung Campuran di kelas IV SDN 2 \\
marikangen.
\end{tabular}

Kata Kunci: pendekatan sinergis, pembelajaran berkelompok, hasil belajar, matematika.

Submitted Feb 22, 2020 | Revised Mar 24, 2020 | Accepted Mar 26, 2020

\section{Pendahuluan}

Matematika juga merupakan salah satu bidang studi yang memiliki peranan yang sangat penting dalam dunia pendidikan. Salah satu karakteristik matematika adalah mempunyai objek kajian yang bersifat abstrak (Alvian dan Dwikurnaningsih, 2017). Sifat abstrak ini menyebabkan banyak peserta didik mengalami kesulitan dalam menghayati dan memahami konsep-konsep matematika. Pembelajaran matematika di SD lebih menekankan pada aktivitas memanipulasi benda konkret dalam memecahkan masalah untuk memahami konsep-konsep matematika. Masalah utama pendidikan formal dewasa ini adalah masih rendahnya daya serap siswa terhadap pembelajaran (Nahdi, 2019). Ini merupakan sebuah permasalahan yang muncul dari aktivitas pembelajaran yaitu pembelajaran yang masih bersifat konvensional, termasuk pembelajaran matematika di sekolah dasar. Penyebab rendahnya mutu pendidikan Menurut 
Soedijarti (Mulyana, 2008: 4) adalah kegiatan pembelajaran di Indonesia pada saat ini tidak lebih dari mencatat, menghafal, dan mengingat kembali dan tidak menerapkan pendekatan modern dalam proses pembelajaran.

Matematika diajarkan di SD dengan semua jenis dan program serta dengan jumlah jam yang relatif banyak bila dibandingkan dengan mata pelajaran lainnya. Meskipun matematika mempunyai jam pelajaran yang relatif banyak, tetapi kenyataan menunjukkan bahwa matematika di SD masih dianggap sebagai mata pelajaran yang sulit dan membosankan bagi peserta didik.

Salah satu materi pada mata pelajaran matematika yaitu bilangan pecahan. Penyelesaian soal operasi hitung bilangan pecahan membutuhkan pemahaman konsep yang lebih sulit dibandingkan dengan operasi hitung bilangan lainnya, sehingga banyak peserta didik yang mengalami kesulitan dalam memahami operasi hitung bilangan pecahan sehingga hasil belajar operasi hitung bilangan pecahan masih rendah. Berdasarkan hasil pengamatan dan informasi yang diperolah dari guru dan siswa Kelas IV SD Negeri 2 Marikangen Kecamatan Plumbon diperoleh informasi bahwa masih banyak siswa yang mengalami kesulitan dalam mata pelajaran matematika khususnya pada pokok bahasan operasi hitung bilangan pecahan. Harus diakui bahwa standar kompetensi dan kompetensi dasar pembelajaran Matematika yang dilaksanakan di Kelas IV SD Negeri 2 Marikangen Kecamatan Plumbon Kabupaten Cirebon yang dilakukan peneliti hasilnya masih jauh yang diharapkan tercapai.

Penyebab utama tidak tercapainya prestasi belajar yaitu metode pembelajaran yang diterapkan terlalu monoton dan menjemukan bagi para siswa. Akibatnya siswa dalam menangkap setiap pelajaran yang disampaikan oleh guru bengong, malas, bosan dan kurang bergairah. Terbukti dari hasil observasi, nilai evaluasi harian pada tahun 2019 semester genap Kelas IV SD Negeri 2 Marikangen Kecamatan Plumbon Kabupaten Cirebon dalam materi “Operasi Hitung Bilangan Campuran” mencapai 20,83 \% ( 5 siswa ) dari 38 siswa yang dinilai sudah memahami tentang materi tersebut.

Dari uraian diatas jelas bahwa metode mengajar itu sangat mempengaruhi proses belajar. Apabila guru mengajar dengan metode yang kurang baik maka akan mempengaruhi belajar siswa yang kurang baik pula. Guru yang biasa mengajar dengan metode ceramah saja, akan menjadikan siswa bosan, pasif, tidak minat belajar. Oleh karena itu guru dituntut menggunakan metode lain atau metode-metode baru yang disesuaikan dengan situasi dan kondisi belajar, agar motivasi dan minat siswa untuk belajar tetap tinggi dan semangat dalam mengajar dan akhirnya tujuan belajar dapat tercapai dengan efektif dan efisien, cepat dan tepat.

Berdasarkan hal tersebut, maka perlu adanya perlakuan yang diduga dapat lebih mengefektifkan kegiatan belajar peserta didik dan mengurangi peran sentral guru dalam proses pembelajaran Bahasa Indonesia yaitu dengan menggunakan Strategi Pengajaran Sinergis. Menurut Zaini (2008), "Strategi ini merupakan perubahan langkah yang sesungguhnya, strategi ini memungkinkan para siswa yang memiliki pengalaman berbeda dalam mempelajarai materi yang sama untuk saling membandingkan catatan." Menurut Silberman (2006:128) metode synergetic teaching memungkinkan para peserta didik yang memiliki pengalaman berbeda dalam mempelajari materi yang sama untuk saling membandingkan catatan. Strategi ini juga membuat peserta didik lebih mudah untuk memahami materi dengan berbagi pengalaman belajar, selain dapat membuat temannya mengerti dengan yang dijelaskan maka peserta didik yang menjelaskan juga akan bertambah paham terhadap materi yang dipelajari. Strategi ini 
dapat diterapkan dalam segala umur, memungkinkan setiap kelompok untuk saling berbagi informasi dengan kelompok-kelompok lain sehingga terjalin komunikasi yang bisa mengaktifkan siswa.

Hakekat Model Pendekatan Sinergis Berbasis Kelompok ini adalah merupakan perubahan langkah yang sesungguhnya. Kelebihan Strategi Pengajaran Sinergis tersebut sejalan dengan pendapat Aji (2014), yang mengemukakan kelebihan pengajaran sinergis sebagai berikut. (1) Siswa lebih mandiri dalam menyelesaikan masalah, (2) Siswa mampu berinteraksi dan berkomunikasi dengan siswa lainnya, (3) Menghilangkan rasa malu dan kaku dan kaku dalam menyampaikan pendapat atau hasil belajar yang mereka peroleh. Metode ini memungkinkan para siswa yang memiliki pengalaman berbeda dalam mempelajari materi yang sama untuk saling membandingkan. Aspek-aspek tersebut aspek-aspek pokok pada pembelajaran Matematika sebagai proses. Sehingga dengan metode pembelajaran sinergis Berbasis Kelompok siswa dapat mengamati sendiri, merasakan, memegang suatu obyek, bekerja menggunakan alat dan bahan, yang pada akhirnya akan ,memudahkan siswa untuk mengingat materi pelajaran yang telah dipelajarinya. Beberapa hasil penelitian yang telah dilakukan diantaranya oleh Netriwati (2012), Annisa dkk. (2013), Azis dan holis (2014), serta Muyawaroh dan Erwanto (2017) menunjukkan pendekatan sinergis cukup berhasil dalam meningkatkan hasil belajr siswa.

\section{Metode Penelitian}

Jenis penelitian yang digunakan dalam penelitian ini adalah penelitian tindakan kelas atau Classroom Action Research (CAR). Menurut Arikunto (2006 : 91), penelitian tindakan kelas merupakan suatu pencermatan terhadap kegiatan yang sengaja dimunculkan, dan terjadi dalam sebuah kelas. Penelitian tindakan kelas dilakukan oleh seorang guru di dalam kelasnya sendiri melalui refleksi diri, dengan tujuan untuk memperbaiki kinerjanya sebagai guru, sehingga hasil belajar siswa menjadi meningkat (Wardani, 2007). Adapun Desain PTK yang digunakan yaitu model siklus menurut Kemis dan Mc.Taggart (Suyanto, 1997 : 16) yaitu terdiri dari empat komponen yaitu :

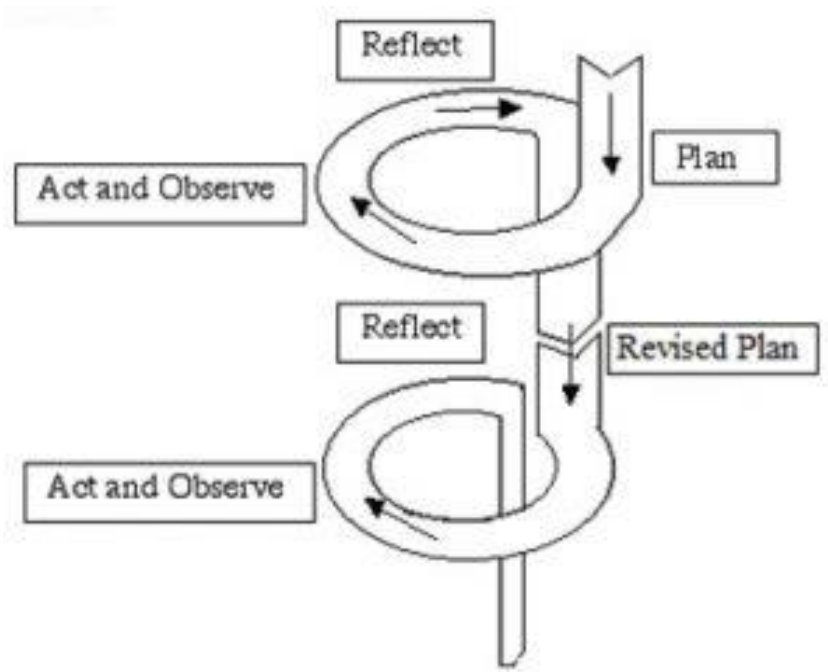

Gambar 1. Alur Penelitian Tindakan Kelas (Kasbolah, 1998). 
PTK ini dilaksanakan berdasarkan tahapan-tahapan sebagai berikut: "(1) merencanakan tindakan, (2) melaksanakan tindakan, (3) melaksanakan observasi, (4) melakukan refleksi." (Kasbolah, 1998: 78). Penelitian ini sesuai dengan karakteristik penelitian tindakan kelas yang dikemukakan oleh Suyanto. Tahapan penelitian yang digunakan dalam penelitian ini berbentuk siklus, yang dibuat dalam bentuk rencana pelaksanaan pembelajaran. Sedangkan Langkah-langkah pembelajaran berdasarkan pada langkah-langkah pendekatan sinergis berbasis kelompok. Tahapan-tahapan pada siklus pertama dirancang dari hasil refleksi kegiatan pembelajaran sehari-hari. Sedangkan tahapan-tahapan pada siklus kedua dirancang dari hasil refleksi siklus pertama. Maka dengan cara demikian diharapkan pada siklus kedua dapat meningkatkan hasil belajar siswa melalui pendekatan sinergis pada siswa Kelas IV SD Negeri 2 Marikangen.

Prosedur penelitian tindakan kelas dilakukan dengan dua siklus, dan tiap siklus dilaksanakan sesuai dengan perubahan yang dicapai dan desain faktor yang diteliti. Untuk mengetahui efektifitas pembelajaran di Kelas IV SD Negeri 2 Marikangen Kecamatan Plumbon Kabupaten Cirebon dilakukan observasi terhadap kegiatan pembelajaran yang dilakukan oleh guru, dan wawancara baik dengan guru maupun siswa. Melalui kegiatan ini dapat dilakukan musyawarah antara guru dengan observer untuk menetapkan tindakan yang paling tepat dalam rangka meningkatkan efektifitas pembelajaran di kelas IV.

Subjek penelitian tindakan kelas ini adalah siswa Kelas IV SD Negeri 2 Marikangen tahun ajaran 2018/2019 berjumlah 36 siswa, Subyek penelitian ini diambil secara keseluruhan, karena asumsikan karakteristik dan kemampuan dianggap sama. Dan peneliti ingin mencari strategi pembelajaran yang efektif untuk meningkatkan pemahaman dan hasil belajar siswa.

Data yang dikumpulkan yaitu hasil penilaian prestasi siswa dengan menerapkan metode konvensional, dan hasil pengamatan proses belajar yang meliputi metode pendekatan, materi pembelajaran dan performen guru/ instruktur

Data penelitian ini dianalisis dengan menggunakan pendekatan kuantitatif dan kualitatif secara bersama-sama. Pendekatan kualitatif digunakan untuk memberikan deskripsi tentang pandangan dan pendapat dari subyek penelitian. Pendekatan kuantitatif digunakan dengan cara mencatat peristiwa hasil prestasi belajar siswa sebelum adanya penelitian, kemudian diadakannya penelitian tindakan kelas pada siklus pertama dan kedua. Dengan pengelompokan data, maka akan ditemukan nilai rendah dan nilai tinggi serta ditemukan nilai rata-ratadari sebelum adanya penelitian tindakan kelas, ketika diadakan dan ada perbaikan.

\section{Hasil dan Pembahasan}

Kegiatan pembelajaran Mataematika dalam materi "Operasi Hitung Bilangan Campuran” di Kelas IV SD Negeri 2 Marikangen Kecamatan Plumbon Kabupaten Cirebon pada penelitian tindakan kelas ini dilaksanakan 2 siklus, masing-masing siklus terdiri dari studi pendahuluan, perencanaan, tindakan, observasi dan refleksi kegiatan yang dilaksanakan. Pada awal pembelajaran guru memberikan motivasi yang menuntun siswa untuk mengingat kembali materi yang akan dibahas, memberikan motivasi kepada siswa agar ikut aktif berperan serta dalam proses belajar, serta menginformasikan tentang kompetensi yang harus dikuasai, menggunakan Model Pendekatan Sinergis Berbasis Kelompok pada mata pelajaran yang telah dilaksanakan. 
Selama pelaksanaan penelitian penulis melakukan kolaborasi dengan guru lain dalam menyusun rencana penelitian, yang meliputi: 1) tujuan pembelajaran, 2) kompetensi dan materi pembelajaran, 3) strategi pembelajaran berupa Model pembelajaran, serta sumber belajar dan 4) evaluasi hasil belajar. Pada awal pembelajaran, observasi dilakukan terhadap guru membuka pelajaran seperti apersepsi terhadap materi yang akan dibahas dan memberikan motivasi kepada siswa.

Selama pelaksanaan tindakan, kegiatan di kelas meliputi aktivitas guru dan siswa diamati dengan menggunakan lembar observasi. Dari data hasil observasi siklus kesatu dan kedua dapat disimpulkan bahwa aktivitas guru dan siswa sudah mengalami peningkatan.pada proses pembelajaran, guru memberikan apersepsi yang dapat memancing siswa untuk bertindak lebih aktif. Hal ini tidak lepas dari peran guru dalam menyampaikan materi, yaitu guru lebih menekankan pemahaman siswa terhadap materi dengan menggunakan pendekatan sinergis. Pada siklus II, guru menggunakan pendekatan sinergis cukup baik sehingga siswa lebih memahami bagaimana cara menyelesaikan soal latihan. Hal ini berdampak positif pada hasil belajar siswa yang mengalami peningkatan.

Pada setiap siklus, dilakukan tes hasil belajar siswa setelah pembahasan suatu materi ajar selesai. Hasil tes dari semua siswa Kelas IV SD Negeri 2 Marikangen dapat dilihat pada tabel berikut:

Tabel 1. Nilai Evaluasi Belajar Siswa pada Tiap Siklus

\begin{tabular}{clcccc}
\hline No & \multicolumn{1}{c}{ N a m a } & L/P & Awal & Siklus I & Siklus II \\
\hline 1 & Adi Permana & $\mathrm{L}$ & 40 & 60 & 70 \\
2 & Ahmad Sutirna & $\mathrm{L}$ & 40 & 60 & 70 \\
3 & Ahmad Wijdan Naim & $\mathrm{L}$ & 50 & 50 & 80 \\
4 & Aida Salab Ila Alagn & $\mathrm{P}$ & 60 & 70 & 80 \\
5 & Alfiah & $\mathrm{P}$ & 40 & 50 & 80 \\
6 & Ilya Auliya Putri & $\mathrm{P}$ & 60 & 70 & 80 \\
7 & Amelia Putri & $\mathrm{P}$ & 40 & 70 & 80 \\
8 & Aprila Nurhaliza & $\mathrm{P}$ & 60 & 80 & 80 \\
9 & Bayu Legiansyah & $\mathrm{P}$ & 60 & 70 & 70 \\
10 & Cantika Tiara Safitri & $\mathrm{P}$ & 50 & 70 & 70 \\
11 & Deva Supriyatna & $\mathrm{P}$ & 70 & 80 & 90 \\
12 & Dewi Saepuna & $\mathrm{P}$ & 50 & 60 & 80 \\
13 & Devi Oktavia Yulian & $\mathrm{P}$ & 70 & 80 & 80 \\
14 & Dwi Rahayu & $\mathrm{P}$ & 40 & 70 & 80 \\
15 & Een Hendika Saputra & $\mathrm{L}$ & 40 & 70 & 80 \\
16 & Eva Farhatul Jahra & $\mathrm{P}$ & 70 & 70 & 80 \\
17 & Fergi Fergiana & $\mathrm{P}$ & 60 & 70 & 80 \\
18 & Gilang Septiana & $\mathrm{L}$ & 40 & 50 & 70 \\
19 & Iin Bhayinah & $\mathrm{P}$ & 80 & 80 & 90 \\
20 & Iis Nurazizah & $\mathrm{L}$ & 50 & 60 & 70 \\
21 & Ike Rumsari & $\mathrm{L}$ & 70 & 80 & 90 \\
22 & Laura Riananda P. & $\mathrm{P}$ & 70 & 80 & 90 \\
23 & Mopik Ibrahim & $\mathrm{L}$ & 70 & 80 & 90 \\
24 & Moh.Irwan Iis Wara & $\mathrm{L}$ & 50 & 70 & 80 \\
25 & Moh.Jaenudin & $\mathrm{L}$ & 70 & 80 & 90 \\
26 & Muhammad Rizki & $\mathrm{L}$ & 70 & 80 & 90 \\
27 & Muh.Agni Ahyar Runs & $\mathrm{L}$ & 40 & 70 & 80 \\
28 & Najwa Fauzian & $\mathrm{P}$ & 70 & 80 & 90 \\
29 & Oom Rohmatul Maul & $\mathrm{P}$ & 70 & 80 & 90 \\
\hline
\end{tabular}


66 Sukari, Penerapan Pendekatan Sinergis Berbasis Kelompok...

\begin{tabular}{|c|c|c|c|c|c|}
\hline 30 & Purwitasari & $\mathrm{P}$ & 40 & 70 & 80 \\
\hline 31 & Putri Mega Utami & $\mathrm{P}$ & 50 & 70 & 80 \\
\hline 32 & Raudlatul Anwar & $\mathrm{L}$ & 60 & 70 & 80 \\
\hline 33 & Raisya Putri Natasy & $\mathrm{P}$ & 50 & 60 & 70 \\
\hline 34 & Rendi Pratama & $\mathrm{L}$ & 50 & 60 & 70 \\
\hline 35 & Rio Fuad Rahrudin & $\mathrm{L}$ & 40 & 70 & 80 \\
\hline 36 & Riqqi Fuadi & $\mathrm{L}$ & 60 & 80 & 90 \\
\hline & Jumlah & & 2050 & 2530 & 2910 \\
\hline & Rata-rata & & 57 & 70.25 & 81 \\
\hline & Peraih nilai 70 ke atas & & $12=31,6 \%$ & $29=76,3 \%$ & $40=100 \%$ \\
\hline & Peraih nilai 70 ke bawah & & $26=68.4 \%$ & $9=23.7 \%$ & $0=0 \%$ \\
\hline
\end{tabular}

Dari data di atas dapat disimpulkan bahwa, antara nilai siswa pada pra siklus yang belum dikenai tindakan dengan siklus I yang telah dikenai tindakan mengalami kenaikan. Nilai ratarata kelas pada saat pra siklus 57,sedangkan pada saat siklus I mencapai 70,25. Selain itu juga, dari data di atas disimpulkan bahwa nilai siswa pada siklus II mengalami kenaikan bila dibandingkan dengan nilai siswa pada siklus I. Nilai rata-rata kelas pada siklus I yaitu 70,25, sedangkan nilai rata-rata kelas pada siklus II yaitu 81. Hasil penelitian pada siklus II sudah memenuhi kriteria keberhasilan penelitian, selain itu tindakan yang dilakukan dalam proses pembelajarannya sudah terlihat adanya perbaikan.Sehingga tidak dilanjutkan ke siklus berikutnya.

\section{Kesimpulan}

Berdasarkan penjelasan di atas dapat disimpulkan bahwa hipotesis tindakan terbukti, yaitu dengan menerapkan Pendekatan sinergis berbasis kelompok dapat Meningkatkan hasil belajar siswa dalam dalam pembelajaran matematika pada Materi Operasi Hitung Campuran di kelas IV SDN 2 marikangen.

\section{Daftar Pustaka}

Aji, TS. (2014). Pengaruh Metode Synergetic Teaching Terhadap Hasil Belajar Mata Pelajaran Penggunaan Alat Ukur Presisi di SMK Dr. Sutomo Temanggung. Jurnal Pendidikan Vokasional Teknik. Mesin, 2(4), 223-230

Alvian, A. \& Dwikurnaningsih, Y. (2017). Peningkatan Hasil Belajar Menggunakan Pembelajaran Matematika Realistik Berbantuan Media Mistar Bilangan. Jurnal Mitra Pendidikan, 1(2), 21-30.

Anisa dkk. (2013). Efektivitas Strategi Pembelajaran Peningkatan Kemampuan Berpikir (SPPKB) Terhadap Hasil Belajar dan Aktivitas Siswa Menggunakan Strategi Synergetic Teaching. Pancaran, 2(4), hal 100-110.

Arikunto, S. (2006). Prosedur Penelitian Suatu Pendekatan Praktik. Jakarta: Rineka Cipta.

Azis, Abdul dan Nur Kholis. 2014. Pengembangan Perangkat Pembelajaran Aktif (Active Learning) Dengan Strategi Synergetic Teaching Pada Mata Diklat Mengukur BesaranBesaran Listrik Dalam Rangkaian Elektronika Kelas X Di SMK Sunan Drajat Lamongan. Jurnal Pendidikan Teknik Elektro. 3(2), 83-88.

Kasbolah (1998). Penelitian Tindakan Kelas. Malang; Depdikbud. 
Mulyana, T (2008). Pembelajaran Analitik Sinektik Untuk Meningkatkan Kemampuan berpikir Kritis dan Kreatif Matematik Siswa Sekolah Menengah Atas.Disertasi pada SPs UPI Bandung. Tidak Diterbitkan.

Nahdi, DS. (2019). Efektivitas Pendekatan Brainstorming Teknik Round-Robin Dalam Meningkatkan Kemampuan Komunikasi Matematis Siswa Sekolah Dasar. Muallimuna: Jurnal Madrasah Ibtidaiyah. 5(1). 11-22.

Netriwati. (2012). Penerapan Strategi Synergetic Teaching Untuk Meningkatkan Hasil Belajar Mahasiswa Dalam Pembelajaran Strategi Belajar Mengajar Matematika di IAIN Raden Inttan Lampung. Jurnal Ilmiah Ilmu Pendidikan. XII (2), 47-52.

Silberman, M. (2006). Active Learning 101 Strategi Pembelajaran Aktif. (terjemahan Komarudin Hidayat) Yogyakarta: Pustaka Insan Madani.

Suyanto.(1997). Pedoman pelaksaaa penelitian kelas. Jakarta: Dirjen Dikti.

Wardani. (2007). Penelitian Tindakan Kelas. Jakarta: Universitas Terbuka.

Zaini, H. (2008). Srategi pembelajaran aktif. Yogyakarta: Insan Mandiri. 